\title{
An Empirical Analysis on the Application of Crime Prevention Through Environmental Design (CPTED) in Urban Park Area - Targeting to the Yangjae Citizen's Forest in Seochogu, Seoul
}

\author{
Jeong-Ho Kim ${ }^{1}$, Won-Jun Choi ${ }^{2}$, and Yong-Han Yoon ${ }^{1}$ * \\ 1 Department of Green Technology Convergence, Konkuk University, Chungju 380-701, South Korea \\ ${ }^{2}$ Department of Green Technology Convergence, Graduate School Konkuk University, Chungju 380-701, South Korea
}

\begin{abstract}
The study revolved around the forests of Yangjae Citizen's Forest, a park where the Crime Prevention Through Environmental Design (CPTED) was applied. The survey methods for analysis are as follows. From August to October, a total of eight surveys were conducted and 147 of the 300 samples collected were utilized for analysis. According to the results of the survey, $43.5 \%$ of participants were males and $56.5 \%$ were females. The highest number of participants visited the forest at midday and aged twenties visited most among all age groups. The participants visited the forest mostly with family and the main purpose of visit was for walking exercise including strolling. In case of criminal experience two sexual harassment (6.0\%), and a fraud crime (3.0\%) were tallied. Insecurity analysis resulted that "other users' drinking" and "few Closed-Circuit Televisions (CCTVs)" were found to increase visitor's insecurity. According to the psychological security analysis, participants reported they felt safer in open space than the enclosed areas. They also responded that dense wooded areas along the trails would increase the level of insecurity, while open space and resting areas were effectively relieve unsafe feelings. CCTVs and lighting fixtures facilities in the study area play an important role to effectively manage the park to prevent crime.
\end{abstract}

Keywords: anxiety, green space structure, neighborhood park, psychological security

\section{Introduction}

Parks in the city are making environmental and ecological contributions such as microclimate control and encouraging citizens to participate in various leisure activities, thereby increasing natural and social values. Parks in the urban center that perform such diverse roles are also becoming vulnerable to more and more crimes due to rapid urbanization and overpopulation, turning into a place of social interest (Kang and Park, 2013). According to the National Police Agency statistics (https://www.police.go.kr/), the number of crimes that occurred in the park doubled in 2010 (5,420 cases) compared to 2001 (2,476 cases). To resolve the issues of the annually increasing crimes (Sohn et al., 2015) and anxiety about crimes as well as to promote security about space, the Crime Prevention Through Environmental Design (CPTED) is being implemented (Bark et al., 2009). Systematic studies and empirical researches are conducted in various perspectives to apply CPTED.

Received: October 17, 2017, Revised: January 26, 2018, Accepted: February 5, 2018

First author: Jeong-Ho Kim, E-mail: hoya1209@kku.ac.kr, ORCID: 0000-0002-7903-1664

*Corresponding author: Yong-Han Yoon, E-mail: yonghan7204@kku.ac.kr, ORCID: 0000-0003-4797-0146 
To begin with, previous studies in terms of system include studies on institutionalization of through CPTED (Shin et al., 2008; Bark et al., 2009) and plans to implement Korean-style CPTED for domestic application (Lee et al., 2008), most of which are covering administrative procedures and institutionalization of CPTED application. Furthermore, studies were conducted on effective budgeting and school safety enhancement to apply CPTED in order to prevent internal and external crimes at school that are constantly increasing (Park and Kim, 2011).

Studies on CPTED application in the city mostly analyze the key elements of CPTED (Chung and Yang, 2010), or are about the physical effects on CPTED application and limitations in terms of sustainable urban development (Seo, 2016). In the field of architecture, studies were conducted on the application and components of CPTED as well as anxiety around living zones such as apartment complexes and schools (Park et al., 2010; Park 2011; Park and Kim, 2011), and also on analysis of living zones and physical environment for CPTED application such as physical status analysis of crimes that occurred in crime-ridden districts (Shin and Kim, 2015). Moreover, some studies in urban architecture claimed that, in academic analysis of CPTED application, physical and environmental elements affect not only crimes but also anxiety (Park et al., 2010; Han et al., 2009; Simon, 2002; Johnston, 2001).

In landscaping and facilities, studies were conducted on lighting such as a CPTED approach in installing security lights (Jeong and Jung 2008), and prevention of crimes and accidents by studying safe color sense and lighting (Lee et al., 2015). Kang and Park (2013) conducted a study on building a safe park in the perspective of CPTED with focus on park design, and came up with the causes and measures for deviation, crimes or anxiety at the park in applying CPTED to the park. Sohn et al. (2015) categorized neighborhood parks into different types according to the level of CPTED application in a study that develops evaluation indexes and evaluates each type of CPTED application, thereby performing an evaluation of safety, but this was limited only to park equipment and facilities.

As such, there are many studies on CPTED, but most of the studies and administrative procedures are concentrated on alleys or housing areas of urban centers. In particular, CPTED techniques currently applied to parks have been mostly used in architecture, causing the issue of not applying the techniques that must be preferentially applied to parks (Sohn et al., 2015).

Therefore, this study is to determine the effects of physical and environmental factors of green space on stability and anxiety, as well as the elements that must be considered in actually applying CPTED to urban parks, by focusing on Yangjae Citizens' Forest that is a park where CPTED is applied. In addition, this study determines the priorities of landscape design and management plans for crime-ridden areas in the park by conducting a survey among users, thereby presenting a CPTED plan suitable for urban parks.

\section{Research Methods}

\section{Study area}

The study area is Yangjae Citizens' Forest located in 99 Maeheon-ro, Seocho-gu, Seoul, which has many users and is an old park built a long time ago in the urban center. Research data were collected by a survey of park users and field study. Yangjae Citizens' Forest is a park built near Yangjae Interchange that is the gateway to Seoul for the 1986 Asian Games and 1988 Summer Olympics in Seoul. Its area is 25.7 ha and it has about 43 species of trees such as pine, zelkova, Manshurian fullmoon maple, horse chestnut and nut pine, forming a structure of diverse plantations but without continuity or natural connection except for nut pine (Kim et al., 2015; Kim, 1999). Facilities include an outdoor wedding venue, basketball court, volleyball court, tennis court and barefoot walking path, as well as the statue and monument of patriot Yun Bong-gil, memorial of Korean Air, Sampoong Memorial Tower, and Memorial Tower for Baengma Guerrilla Unit. 
Yangjae Citizens' Forest was certified as a CPTED park in 2014 and has directional signs, emergency bells, new CCTVs, LED lights, light bars and integrated control system applying crime prevention designs, thereby making it suitable for this study.

In this study, we determined the elements that were not considered in implementing CPTED in the CPTED-certified park Yangjae Citizens' Forest and also the landscape design and management plans for crime-ridden areas in the park, thereby presenting a CPTED plan suitable for the park.

\section{Analysis method}

A survey was conducted among park users to analyze the suitable CPTED application in the park as well as park management and building plan. It was conducted total 8 times for 3 months, from late August to October 2016, which is fall with relatively longer hours of use and greater number of users. There were total 300 samples and we collected 147 of them that meet the objective of this study, but analyzed them while including redundant choices for hours of use, companions and method of use. There were total 34 items in the questionnaire, categorized into causes of insecurity and psychological security, space concerned of crimes, landscape and facility management (Table 1), using a Likert scale to make the subjectivity scale objective. Dummy variables from 1 through 5 were used for each item, and the variables for causes of insecurity and psychological security were rated as 1 "strongly disagree," 2 "disagree," 3 "average," 4 "agree," and 5 "strongly agree." For analysis of space concerned of crimes in the park, 1 was "very safe against crimes," 2 "safe against crimes," 3 "average," 4 "concerned about crimes," and 5 "very concerned about crimes." Dummy variables from 1 through 5 were used to quantify the opinions about landscape and facility management in the park, with 1 "not effective at all," 2 "not very effective," 3 "average," 4 "somewhat effective," and 5 "very effective."

SPSS 18 ver. was used in statistical analysis, and to empirically analyze the application plan of CPTED, analysis was conducted in three parts: basic statistics, reliability analysis of the measurement model, and verification of study. Demographic analysis was conducted for basic statistics and frequency analysis was conducted through descriptive statistics to analyze park safety and crime concerns. Validity analysis of each item was conducted to test the reliability and validity of the measurement model. Lastly, frequency analysis, descriptive statistics and independent samples t-test (t-test) were used to analyze anxiety and psychological safety, concern about crimes, and priorities for landscape and facility management.

\section{Results and Discussions}

\section{Results of basic statistics}

\section{Results of demographic analysis}

The results of demographic analysis to analyze the characteristics of the survey respondents are as follows (Table 2). Out of total 147 respondents, 64 were male (43.5\%) and 83 were female (56.5\%).

By age, respondents in their 20s took up the highest ratio with 46 (31.3\%), followed by 28 in their 30s (19.0\%), 27 in their $10 \mathrm{~s}(18.4 \%), 16$ each in their 50s and 60s (10.9\%), with 40s taking up the least with 14 (9.5\%).

By use, 39 respondents visited the park the most with once a month (26.5\%), followed by 27 respondents 3 times a month (18.4\%), 23 respondents 2 times a month (15.6\%), 23 respondents 4 times a month (15.0\%). One respondent each used the park 17 times and 25 times a month $(0.7 \%)$ with low frequency, but there were 3 respondents using the park 30 times a month (2.0\%) and 6 respondents 20 times a month (4.0\%). 
Table 1. Contents of the survey.

\begin{tabular}{|c|c|}
\hline Question & Content \\
\hline \multirow{7}{*}{$\begin{array}{l}\text { 1. This causes you feel insecure in Yangjae Citizen's } \\
\text { forest. }\end{array}$} & 1-1. Other users' drinking \\
\hline & 1-2. Park is open very late (Open 24 hours) \\
\hline & 1-3. Few CCTVs in the park \\
\hline & 1-4. Thickly wooded trails \\
\hline & 1-5. Few lighting fixtures in the park \\
\hline & 1-6. Blind spots in the park \\
\hline & 1-7. Few park managers in the park \\
\hline \multirow{7}{*}{$\begin{array}{l}\text { 2. Preference of Green Space and Facilities for } \\
\text { psychological security }\end{array}$} & 2-1. Feel unsafe by blind spots created by trees \\
\hline & 2-2. Feel unsafe by thickly wooded areas \\
\hline & 2-3. Enclosed areas are better than open areas for safety \\
\hline & 2-4. Evergreen trees are better than deciduous trees for safety \\
\hline & 2-5. Tall trees are better than shrubs for safety \\
\hline & 2-6. The less the park facilities, the better for safety \\
\hline & 2-7. Feel safe without shortcuts \\
\hline \multirow{10}{*}{$\begin{array}{l}\text { 3. Level of fear of crime in these areas in Yangjae } \\
\text { Citizen's forest }\end{array}$} & 3-1. Green space completely covered with trees \\
\hline & 3-2. Green space partly covered with trees (exposed to sunlight) \\
\hline & 3-3. Rest facilities and landscape greenery \\
\hline & 3-4. Square (open space or grassy open area) \\
\hline & 3-5. Buildings (cafeteria, restroom, a memorial tower) \\
\hline & 3-6. Children's Park (playground) \\
\hline & 3-7. Exercise facilities (acupressure, tennis court) \\
\hline & 3-8. Square surrounded with tall trees \\
\hline & 3-9. Densely wooded trails \\
\hline & 3-10. Road side bike trails \\
\hline \multirow{10}{*}{$\begin{array}{l}\text { 4. What crime prevention is most effective as listed } \\
\text { above? }\end{array}$} & 4-1. Additional CCTV installation \\
\hline & 4-2. Additional lighting fixture installation \\
\hline & 4-3. Landscape design exclusively focusing on shrubs \\
\hline & 4-4. Tree pruning in the park \\
\hline & 4-5. Installation of emergency call box \\
\hline & 4-6. Landscape design ensuring visibility \\
\hline & 4-7. Taking shortcuts should be prohibited \\
\hline & 4-8. Increasing police (park mangers) patrols \\
\hline & 4-9. Bench design to dissuade the homeless \\
\hline & 4-10. Landscape design focusing on tall trees \\
\hline
\end{tabular}

As for time of day to use the forest, there were 154 frequencies including redundant choices. The highest frequency was 56 cases (36.4\%) for "midday" from noon to 3 pm, followed by 21 (13.6\%) for "different every time but mostly daytime," 20 (13.0\%) each for morning (09:00-12:00) and afternoon (15:00-18:00), 14 (9.1\%) for "different every time but mostly at 
Table 2. Demographic analysis.

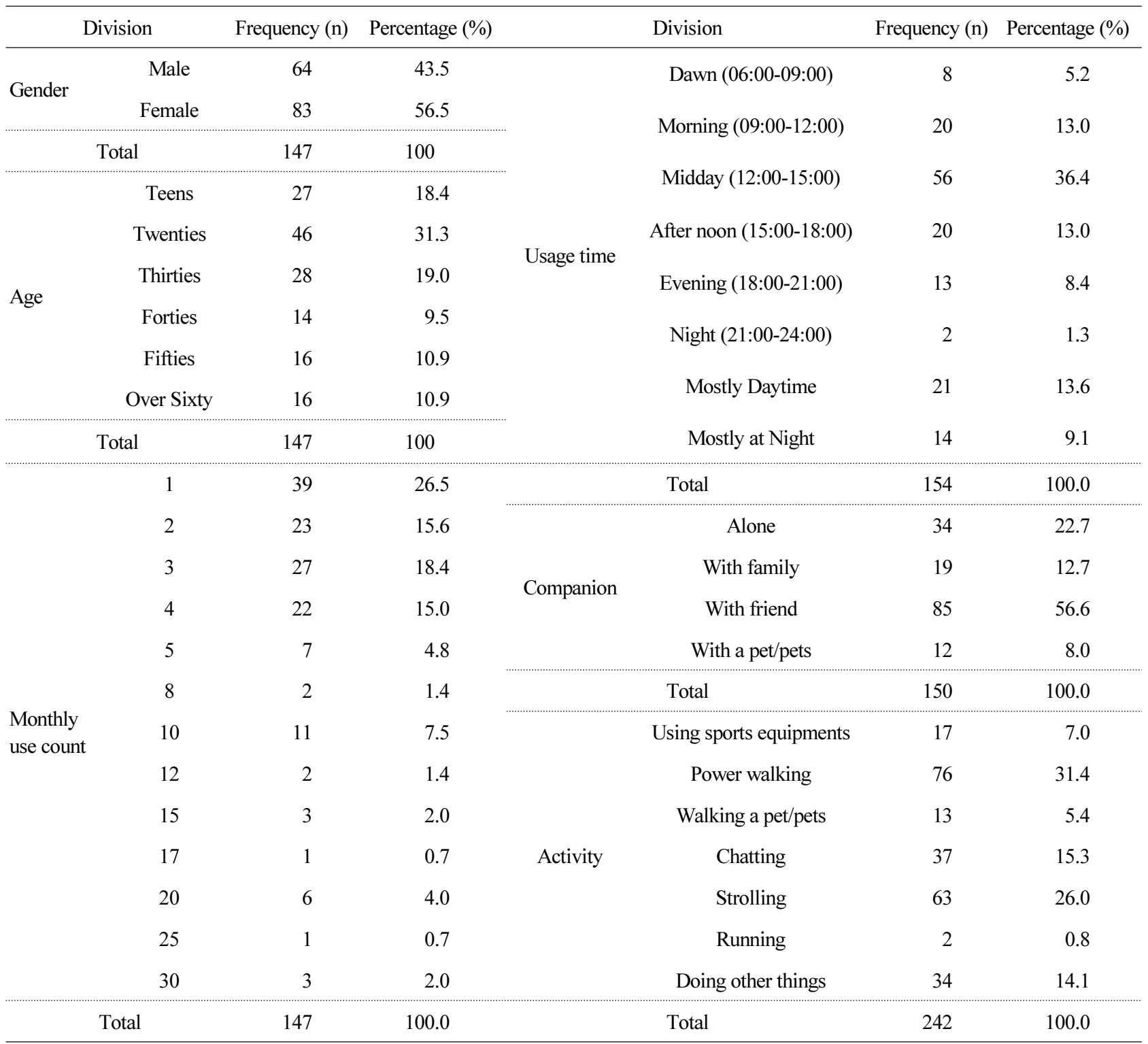

night," 13 (8.4\%) for evening (18:00-21:00), 8 (5.2\%) for morning (06:00-09:00), and 2 (1.3\%) for night (21:00-24:00). As for companions in visiting the park, there were 150 frequencies including redundant choices. 85 cases (56.6\%) showed that they visited the park "with friend or colleague," followed by 34 (22.7\%) "alone," 19 (12.7\%) "with family," and 12 (8.0\%) "with a pet." There were 242 frequencies including redundant choices for activity, with 76 (31.4\%) doing power walking and 63 (26.0\%) just strolling, followed by 37 (15.3\%) chatting, 34 (14.1\%) doing other things, 17 (7.0\%) using sports equipments, $13(5.4 \%)$ walking their pets, and $2(0.8 \%)$ running. Other activities included many hobbies such as skateboarding, playing foot volleyball or basketball, and bike riding, followed by going on a date, watching the view and taking pictures.

\section{Results of analyzing criminal offenses and witnessing}

Table 3 below shows the results of analyzing the survey on crime experience and witnessing. Among 147 cases of using Yangjae Citizens' Forest, 22 (15.0\%) experienced or witnessed crimes, while 125 (85\%) did not have experience. 
Table 3. Criminal experience analysis.

\begin{tabular}{ccccc}
\hline \multicolumn{2}{c}{ Division } & Having been a witness or a victim & Not involved in an incident & Total \\
\hline \multirow{2}{*}{ Criminal incidents } & Frequency (n) & 22 & 125 & 147 \\
& Percentage (\%) & 15.0 & 85.0 & 100.0 \\
\hline
\end{tabular}

Table 4. Classification of criminal offenses type.

\begin{tabular}{rccccccc}
\hline Division & Larceny & Assault and battery & Threat & Fraud & Sexual violence & Others & Total \\
\hline Frequency (n) & 13 & 3 & 9 & 1 & 5 & 2 & 33 \\
Percentage (\%) & 39.4 & 9.1 & 27.3 & 3.0 & 15.2 & 6.0 & 100.0 \\
\hline
\end{tabular}

As for types of criminal offenses (Table 4), there were 33 cases including redundant choices, with the highest being 13 cases (39.4\%) of larceny, followed by $9(27.3 \%)$ of threat and harassment, $5(15.2 \%)$ of sexual violence, $3(9.1 \%)$ of assault and battery, $2(6.0 \%)$ of others, and $1(3.0 \%)$ of fraud. Among others, 2 cases were of sexual harassment, and violent crimes such as sexual violence and threat by injury turned out to be more frequent than other crimes.

\section{Reliability analysis of the measurement model}

Reliability analysis was conducted for the survey results to test the hypotheses of the research model, and the results are as follows. Total 7 items were about anxiety or insecurity in using the park, with high reliability (Cronbach's alpha $=0.848$ ). There were total 7 items about the green space and facilities in Yangjae Citizens' Forest, with average reliability (Cronbach's alpha=0.603). Total 10 items were about space concerned of crimes in the park, with high reliability (Cronbach's alpha $=0.806$ ). Total 11 items were about crime prevention in the park and less fear of crimes, with relatively high reliability (Cronbach's alpha=0.778).

\section{Results of survey analysis}

\section{Analysis of insecurity and psychological security}

As a result of frequency analysis on insecurity factors about park management, the mean was 3.07 and standard deviation was 1.14, indicating that anxiety at Yangjae Citizens' Forest was distributed overall between 1.93 "strongly disagree" and 4.21 "somewhat agree." The factors that promote anxiety in terms of park management and facility were "other users' drinking" (3.71) and "few CCTVs in the park" (3.31). On the other hand, the factors that give insecure feelings to visitors least were "thickly wooded trails" (2.54) and "park is open very late" (2.67).

As a result of the independent samples t-test of psychological security according to the park's landscape management,

Table 5. Reliability analysis result.

\begin{tabular}{lccc}
\hline \multicolumn{1}{c}{ Division } & Division count & Division number & Reliability \\
\hline Insecurity & 7 & $1-1,1-2,1-3,1-4,1-5,1-6,1-7$ & 0.848 \\
Facilities & 7 & $2-1,2-2,2-3,2-4,2-5,2-6,2-7$ & 0.603 \\
Fear of crime & 10 & $3-1,3-2,3-3,3-4,3-5,3-6,3-7,3-8,3-9,3-10$ & 0.806 \\
Solution plan & 11 & $4-1,4-2,4-3,4-4,4-5,4-6,4-7,4-8,4-9,4-10,4-11$ & 0.778 \\
\hline
\end{tabular}


Table 6. Anxiety and psychological safety analysis.

\begin{tabular}{|c|c|c|}
\hline Division & Average & Standard deviation \\
\hline 1-1. Other users' drinking & 3.71 & 1.14 \\
\hline 1-2. Park is open very late (Open 24 hours) & 2.67 & 1.18 \\
\hline 1-3. Few CCTVs in the park & 3.31 & 1.09 \\
\hline 1-4. Thickly wooded trails & 2.54 & 1.18 \\
\hline 1-5. Few lighting fixtures in the park & 3.11 & 1.08 \\
\hline 1-6. Blind spots in the park & 3.11 & 1.10 \\
\hline 1-7. Few park managers in the park & 3.07 & 1.23 \\
\hline Average insecurity levels in park & 3.07 & 1.14 \\
\hline Division & Average & Standard deviation \\
\hline 2-1. Feel unsafe by blind spots created by trees & 2.56 & .99 \\
\hline 2-2. Feel unsafe by thickly wooded areas & 2.70 & 1.05 \\
\hline 2-3. Enclosed areas are better than open areas for safety & 2.10 & .90 \\
\hline 2-4. Evergreen trees are better than deciduous trees for safety & 2.87 & .98 \\
\hline 2-5. Tall trees are better than shrubs for safety & 3.22 & 1.01 \\
\hline 2-6. The less the park facilities, the better for safety & 2.65 & .96 \\
\hline 2-7. Feel safe without shortcuts & 2.76 & 1.11 \\
\hline Average Landscape security & 2.69 & 1.00 \\
\hline
\end{tabular}

the mean was 2.69 and standard deviation was 1.00 , indicating that psychological security was distributed overall between 1.69 "strongly disagree" and 3.69 "average." The result of the t-test according to landscape management showed that most items scored 2 "disagree," with the score relatively high (3.22) for 2-5 "Tall trees are better than shrubs for safety."

Table 7 shows the independent samples t-test of anxiety and psychological security between men and women. In general, women felt unsafe more than men $(p<.05)$, and the gender gap was greatest for 1-5 "Few lighting fixtures in the park" and 1-4 "Thickly wooded trails" ( $p<.01)$, which implied that it is necessary to fix the lightings at the park and prune the planted trees to reduce insecurity for female users. On the other hand, "other users' drinking" turned out to be the biggest factor of anxiety without much statistical significance between men and women $(p>.05)$, indicating that both genders felt unsafe. For psychological security, there was no statistical significance in the gap between men and women $(p>.05)$, with relatively big difference in 2-1 "Feel unsafe by blind spots created by trees" and 2-2 "Feel unsafe by thickly wooded areas" $(p<.05)$.

To reduce anxiety, it would be effective to install CCTVs and lights as already suggested by previous studies (Park and Kim, 2011), and prohibit drinking of users if possible. As a design plan for psychological safety, it is also necessary to resolve the issue of the view blocked by shrubs, and plant tall arbors while avoiding high density planting.

\section{Analysis of space concerned about crimes in the park}

Table 8 shows the analysis of space concerned about crimes in the park, and the relevant spaces were "Green space completely covered with trees" (3.50) and "Densely wooded trails" (3.37). On the other hand, the concern decreased in open green space such as "Green space partly covered with trees (exposed to sunlight)" or "Square surrounded with tall 
Table 7. Psychological safety analysis of male and female.

\begin{tabular}{|c|c|c|c|c|c|}
\hline Division & Gender & Average & Standard deviation & $\mathrm{t}$ & MD \\
\hline \multirow{2}{*}{ 1-1. Other users' drinking } & Male & 3.50 & 1.17 & \multirow{2}{*}{-1.953} & \multirow{2}{*}{-0.37} \\
\hline & Female & 3.87 & 1.10 & & \\
\hline \multirow{2}{*}{ 1-2. Park is open very late (Open 24 hours) } & Male & 2.42 & 1.19 & \multirow{2}{*}{-2.297} & \multirow{2}{*}{$-0.45^{*}$} \\
\hline & Female & 2.87 & 1.15 & & \\
\hline \multirow{2}{*}{ 1-3. Few CCTVs in the park } & Male & 3.05 & 1.12 & \multirow{2}{*}{-2.583} & \multirow{2}{*}{$-0.46^{*}$} \\
\hline & Female & 3.51 & 1.03 & & \\
\hline \multirow{2}{*}{ 1-4. Thickly wooded trails } & Male & 2.25 & 1.04 & \multirow{2}{*}{-2.700} & \multirow{2}{*}{$-0.51 * *$} \\
\hline & Female & 2.76 & 1.25 & & \\
\hline \multirow{2}{*}{ 1-5. Few lighting fixtures in the park } & Male & 2.91 & 1.11 & \multirow{2}{*}{-2.928} & \multirow{2}{*}{$-0.36^{* *}$} \\
\hline & Female & 3.27 & 1.04 & & \\
\hline \multirow{2}{*}{ 1-6. Blind spots in the park } & Male & 2.81 & 1.10 & \multirow{2}{*}{-2.240} & \multirow{2}{*}{$-0.52 *$} \\
\hline & Female & 3.34 & 1.06 & & \\
\hline \multirow{2}{*}{ 1-7. Few park managers in the park } & Male & 2.81 & 1.25 & \multirow{2}{*}{-2.018} & \multirow{2}{*}{$-0.45^{*}$} \\
\hline & Female & 3.27 & 1.19 & & \\
\hline Classification & Gender & Average & Standard deviation & $\mathrm{t}$ & MD \\
\hline \multirow{2}{*}{$2-1$. Feel unsafe by blind spots created by trees } & Male & 2.36 & .98 & \multirow{2}{*}{-2.245} & \multirow{2}{*}{$-0.36^{*}$} \\
\hline & Female & 2.72 & .97 & & \\
\hline \multirow{2}{*}{ 2-2. Feel unsafe by thickly wooded areas } & Male & 2.50 & 1.08 & \multirow{2}{*}{-2.058} & \multirow{2}{*}{$-0.36^{*}$} \\
\hline & Female & 2.86 & 1.00 & & \\
\hline \multirow{2}{*}{ 2-3. Enclosed areas are better than open areas for safety } & Male & 2.17 & .83 & \multirow{2}{*}{.904} & \multirow{2}{*}{0.14} \\
\hline & Female & 2.04 & .96 & & \\
\hline \multirow{2}{*}{ 2-4. vergreen trees are better than deciduous trees for safety } & Male & 2.84 & 1.03 & & 005 \\
\hline & Female & 2.89 & .95 & -.292 & -0.05 \\
\hline & Male & 3.08 & 1.09 & & \\
\hline $2-5$. Iall trees are better than shrubs for satety & Female & 3.33 & .94 & $-1.4 / 1$ & -0.25 \\
\hline 26 The loge the porl focilition the hattor for cofoth & Male & 2.70 & .99 & 632 & 010 \\
\hline 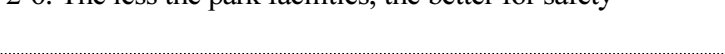 & Female & 2.60 & .94 & .032 & 0.10 \\
\hline 7 Eol cofo without shortoutc 50 & Male & 2.77 & 1.21 & & \\
\hline 2-1. reer sale willioul shoriculs & Female & 2.75 & 1.05 & .100 & 0.02 \\
\hline
\end{tabular}

$\mathrm{MD}=$ Mean difference between mean value of male and female.

$* p<.05, * * p<.01$.

trees." The concern about crimes also decreased remarkably in spaces with high natural surveillance such as rest facilities, equipment, square and exercise facilities. This is similar to a previous study (Kang, 2010) proving that the crime rate decreases in spaces with natural surveillance.

As for the difference between men and women, the difference was significant in 3-1 "Green space completely covered with trees" ( $p<.05)$, but not the rest $(p>.05)$. 
Table 8. Crime apprehension analysis in park.

\begin{tabular}{lcc}
\hline \multicolumn{1}{c}{ Division } & Average & Standard deviation \\
\hline 3-1. Green space completely covered with trees & 3.50 & .78 \\
3-2. Green space partly covered with trees (exposed to sunlight) & 2.61 & .76 \\
3-3. Rest facilities and landscape greenery & 2.53 & .80 \\
3-4. Square (open space or grassy open area) & 2.39 & .82 \\
3-5. Buildings (cafeteria, restroom, a memorial tower) & 2.72 & 1.01 \\
3-6. Children's Park (playground) & 2.78 & .88 \\
3-7. Exercise facilities (acupressure, tennis court) & 2.67 & .77 \\
3-8. Square surrounded with tall trees & 2.8 & .82 \\
3-9. Densely wooded trails & 3.37 & .97 \\
3-10. Road side bike trails & 2.86 & .78 \\
\hline
\end{tabular}

Table 9. Crime apprehension analysis in park between male and female.

\begin{tabular}{|c|c|c|c|c|c|}
\hline Division & Gender & Average & Standard deviation & $\mathrm{t}$ & $\mathrm{MD}$ \\
\hline \multirow{2}{*}{ 3-1. Green space completely covered with trees } & Male & 3.34 & .84 & \multirow{2}{*}{2.209} & \multirow{2}{*}{$-0.29 *$} \\
\hline & Female & 3.63 & .71 & & \\
\hline \multirow{2}{*}{ 3-2. Green space partly covered with trees (exposed to sunlight) } & Male & 2.66 & .78 & \multirow{2}{*}{-.707} & \multirow{2}{*}{0.09} \\
\hline & Female & 2.57 & .75 & & \\
\hline \multirow{2}{*}{ 3-3. Rest facilities and landscape greenery } & Male & 2.58 & .79 & \multirow{2}{*}{-.634} & \multirow{2}{*}{0.09} \\
\hline & Female & 2.49 & .80 & & \\
\hline \multirow{2}{*}{ 3-4. Square (open space or grassy open area) } & Male & 2.44 & .89 & \multirow{2}{*}{-.554} & \multirow{2}{*}{0.08} \\
\hline & Female & 2.36 & .77 & & \\
\hline \multirow{2}{*}{ 3-5. Buildings (cafeteria, restroom, a memorial tower) } & Male & 2.64 & 1.01 & \multirow{2}{*}{.851} & \multirow{2}{*}{-0.14} \\
\hline & Female & 2.78 & 1.00 & & \\
\hline \multirow{2}{*}{ 3-6. Children's Park (playground) } & Male & 2.7 & .87 & \multirow{2}{*}{.873} & \multirow{2}{*}{-0.13} \\
\hline & Female & 2.83 & .89 & & \\
\hline \multirow{2}{*}{ 3-7. Exercise facilities (acupressure, tennis court) } & Male & 2.58 & .75 & \multirow{2}{*}{1.226} & \multirow{2}{*}{-0.15} \\
\hline & Female & 2.73 & .78 & & \\
\hline \multirow{2}{*}{ 3-8. Square surrounded with tall trees } & Male & 2.81 & .83 & \multirow{2}{*}{-.127} & \multirow{2}{*}{0.01} \\
\hline & Female & 2.8 & .81 & & \\
\hline \multirow{2}{*}{ 3-9. Densely wooded trails } & Male & 3.33 & 1.02 & \multirow{2}{*}{.502} & \multirow{2}{*}{-0.08} \\
\hline & Female & 3.41 & .94 & & \\
\hline \multirow{2}{*}{ 3-10. Road side bike trails } & Male & 2.75 & .80 & \multirow{2}{*}{1.559} & \multirow{2}{*}{-0.20} \\
\hline & Female & 2.95 & .76 & & \\
\hline
\end{tabular}

$\mathrm{MD}=$ Mean difference between mean value of male and female.

$* p<.05, * * p<.01$.

In general, there were more concerns about crimes in densely wooded green space, while there were less in open space with natural surveillance. The concern about crimes showed similar results with results about insecurity, but without much difference between men and women.

It is necessary to design the landscape to have natural surveillance in order to reduce crime-ridden areas in the space, and manage and replant the trees that block the view. 


\section{Analysis of landscape and facility management}

Table 10 shows the survey analyzing the landscape and facility management in the park, for which frequency analysis and independent samples t-test were conducted.

Table 10. Effective park management of crime prevention.

\begin{tabular}{lcc}
\hline \multicolumn{1}{c}{ Division } & Average & Standard deviation \\
\hline 4-1. Additional CCTV installation & 4.03 & .84 \\
4-2. Additional lighting fixture installation & 4.04 & .91 \\
4-3. Landscape design exclusively focusing on shrubs & 3.12 & .90 \\
4-4. Tree pruning in the park & 3.24 & .97 \\
4-5. Installation of emergency call box & 3.90 & .96 \\
4-6. Landscape design ensuring visibility & 3.50 & .90 \\
4-7. Taking shortcuts should be prohibited & 3.14 & .99 \\
4-8. Increasing police (park mangers) patrols & 4.01 & .98 \\
4-9. Bench design to dissuade the homeless & 3.65 & .99 \\
4-10. Landscape design focusing on tall trees & 3.27 & .83 \\
\hline
\end{tabular}

Table 11. Effective park management about crime prevention between male and female.

\begin{tabular}{|c|c|c|c|c|c|}
\hline Division & Gender & Average & Standard deviation & $\mathrm{t}$ & MD \\
\hline \multirow{2}{*}{ 4-1. Additional CCTV installation } & Male & 4.00 & .93 & \multirow{2}{*}{-.342} & \multirow{2}{*}{-0.05} \\
\hline & Female & 4.05 & .78 & & \\
\hline \multirow{2}{*}{ 4-2. Additional lighting fixture installation } & Male & 3.97 & 1.02 & \multirow{2}{*}{-.846} & \multirow{2}{*}{-0.13} \\
\hline & Female & 4.10 & .81 & & \\
\hline \multirow{2}{*}{ 4-3. Landscape design exclusively focusing on shrubs } & Male & 3.05 & .79 & \multirow{2}{*}{-.840} & \multirow{2}{*}{-0.12} \\
\hline & Female & 3.17 & .97 & & \\
\hline \multirow{2}{*}{ 4-4. Tree pruning in the park } & Male & 3.05 & 1.00 & \multirow{2}{*}{-2.203} & \multirow{2}{*}{$-0.35^{*}$} \\
\hline & Female & 3.40 & .92 & & \\
\hline \multirow{2}{*}{ 4-5. Installation of emergency call box } & Male & 3.27 & 1.00 & \multirow{2}{*}{-1.272} & \multirow{2}{*}{-0.20} \\
\hline & Female & 3.47 & .94 & & \\
\hline \multirow{2}{*}{ 4-6. Landscape design ensuring visibility } & Male & 3.95 & .93 & \multirow{2}{*}{.535} & \multirow{2}{*}{0.09} \\
\hline & Female & 3.87 & .98 & & \\
\hline \multirow{2}{*}{ 4-7. Taking shortcuts should be prohibited } & Male & 3.39 & .97 & \multirow{2}{*}{-1.335} & \multirow{2}{*}{-0.20} \\
\hline & Female & 3.59 & .84 & & \\
\hline \multirow{2}{*}{ 4-8. Increasing police (park mangers) patrols } & Male & 3.09 & 1.03 & \multirow{2}{*}{-.453} & \multirow{2}{*}{-0.07} \\
\hline & Female & 3.17 & .96 & & \\
\hline \multirow{2}{*}{ 4-9. Bench design to dissuade the homeless } & Male & 4.05 & 1.03 & \multirow{2}{*}{.436} & \multirow{2}{*}{0.07} \\
\hline & Female & 3.98 & .94 & & \\
\hline \multirow{2}{*}{ 4-10. Landscape design focusing on tall trees } & Male & 3.69 & .97 & \multirow{2}{*}{.442} & \multirow{2}{*}{0.07} \\
\hline & Female & 3.61 & 1.01 & & \\
\hline
\end{tabular}

$\mathrm{MD}=$ Mean difference between mean value of male and female.

$* p<.05$. 
Most respondents rated facility management from 3 "average" to 4 "effective," and decided that installing CCTVs and emergency call boxes or having police or park managers regularly patrol around the park would prevent crimes and reduce the fear of crimes. On the other hand, for analysis about landscape and facility management, design for natural surveillance such as installing security lights and securing visibility would prevent crimes and reduce the fear of crimes. The priorities for landscape and facility management in the park were in the order of 4-2 $>4-1>4-9>4-6>4-10>4-7>$ $4-5>4-4>4-8>4-3$.

As a result of independent samples t-test between men and women in park landscape and facility management, significance was found in 4-4 "Tree pruning in the park" $(p<.05)$, but not in other items $(p>.05)$, indicating that there was not much difference overall between men and women in park management.

Overall, the participants responded that criminal damage and concern would be reduced by facility management. In particular, they responded that installing CCTVs and increasing emergency call boxes would be most effective, and preferred prevention through artificial surveillance such as patrol of police or park managers, but also preferred psychological security through natural surveillance such as security lights and short shrubs.

\section{Conclusion}

This study is to determine the factors that are not considered in implementing the current CPTED to parks by examining Yangjae Citizens' Forest where CPTED is already applied, as well as to determine the landscape design and management plans of crime-ridden areas in the park, thereby presenting a suitable CPTED plan for the park.

Yangjae Citizens' Forest was studied in terms of insecure factors of park management, space with concerns about crimes in the park, and park landscape and facility management. The insecurity factors of park management were "other users' drinking" and "insufficient CCTVs," and anxiety factors of landscape management were generally favorable, but enclosed areas due to shrubs increased insecurity while open green space gave greater psychological security. In terms of space with concerns about crimes in the park, the respondents felt unsafe in densely wooded trails or forests, while natural surveillance of open space like rest or exercise facilities was effective to resolve this anxiety. As for park facility management, the respondents preferred artificial surveillance such as CCTV, emergency call boxes and patrols, while open space like the square or plaza showed high psychological security. For landscape, natural surveillance reduced anxiety such as installing security lights and planting short shrubs.

In summary of the results above, when designing CPTED for urban parks, it is necessary to implement artificial surveillance by increasing CCTVs or patrols in densely wooded green space or trails, or promote natural surveillance by installing lights and designing open landscape. In particular, drinking in the park must be avoided by imposing administrative sanctions with notices and signs, and laws about CCTVs and emergency call boxes in the park must be applied. Furthermore, it is necessary to design CPTED from the landscaping stage of the park to avoid enclosed areas or blind spots due to trees.

The results of this study can be the data to verify the factors omitted in applying CPTED to urban parks, but are limited in terms of not clarifying the precise relations between the current state of green space and anxiety like the cases in other countries. Therefore, it is necessary to conduct various experiments in a more complicated structure and green environment, and provide guidelines and manuals for landscape design as well as facility and tree management through a more quantitative measurement. 


\section{Reference}

Bark, H.M., J.T. Hwang, J.I. Hwang, E.G. Hwang, and K.D. Park. 2009. How to Institutionalize CPTED in Korea (II). Report No. 09-36 pp:27-405. Seoul, Korea: Korean Institute of Criminology. Retrieved from https://www.kic.re.kr/ pubdata/public/Read.jsp?paramNttID $=4349$ \&paramPage $=1$

Chung, I.H. and J.S. Yang. 2010. A Study on Prevention of Urban Crime Using CPTED. J. Korean Living Environ. Syst. 17(4):434-446.

Han, H.S., J.I. Yoo, and J.Y. Ham. 2009. Empirical analysis of politic effective to the Crime Prevention Through Environmental Design - Based on the Survey of the Mok-dong Apartment Residents. J. Resid. Environ. Inst. Korea 7(2):175-198.

Jeong, W.J. and J.S. Jung. 2008. A study on the actual operating conditions of guard lamps and its maintenance problems. J. Korean Inst. Illum. Electr. Install. Eng. 22(8):89-95.

Johnston, L. 2001. Crime, Fear and Civil Policing. Urban Stud. 38(5-6):959-976.

Kang, S.J. 2010. Study on the crime risk assessment for the urban safety management. PhD. Diss., Korea Univ., Seoul, Korea.

Kang, S.J. and M.R. Park. 2013. A Study on the Safer Parks using CPTED Principles. J. Archit. Inst. Korea Plan. Des. 29(3):125-134.

Kim, D.W. 1999. Alternative Models of Yangjae Citizen's Park in Seoul, korea. MS thesis, Univ. of Seoul., Seoul, Korea.

Kim, J.H., D.K. Oh, and Y. H. Yoon. 2015. summer - Targeting to the Yangjae citizen's forest in Seochogu, Seoul. Urban Des. 16(6):19-33.

Lee, H.J., S.J. Kang, S.Y. Park, and K.H. Lee. 2015. A Study on the Application of CPTED on Public Design on the Design Seoul Street. Seoul Inst. 16(2):149-164.

Lee, J.S., H.H. Park, and S.K. Oh. 2008. A Study on the Crime Prevention Through Environmental Design (CPTED) Strategy for the Application in Korea : A Preliminary Inquiry. J. Korean Reg. Dev. Assoc. 20(2):213-232.

Park, J.E., S.J. Kang, and K.H. Lee. 2010. An Analysis on the Factors of CPTED and Crime and Fear of Crime in Outdoor Space of Multi-Family Housings. J. Archit. Inst. Korea Plan. Des. 26(5):103-112.

Park, S.C. 2011. Prioritization of Educational Spaces for School CPTED. J. Archit. Inst. Korea Plan. Des. 27(1):73-80.

Park, S.C. and J.W. Kim. 2011. Expected Effect and Applicable Alternatives of CPTED Elements for School Crime Prevention. J. Archit. Inst. Korea Plan. Des. 27(10):43-50.

Seo, J.K. 2016. Critical review of Urban Environmental Design for Crime Prevention as Sustainable Urban Development : Focusing on the Approaches of Environmental Design and Secured by Design. J. Local Gov. Stud. 28(1):51-75.

Shin, E.G., K.R. Park, Y.O. Jung, K. Kim, H.H. Park, and K.G. Hong. 2008. How to institutionalize CPTED in Korea(I). Report No. 08-15. pp:27-565. Seoul, Korea:Korean Institute of Criminology. Retrieved from https://www.kic.re.kr/ pubdata/public/Read.jsp?paramNttID=4307\&paramPage=1

Shin, M.K. and E.M. Kim. 2015, May. Analysis of Physical Environment Factors of Crime Using GIS and CPTED. Proceedings of National Geographic Information Institute (5):99-100. Jeju, Korea:Korean Society for Geospatial Information Science.

Simon, J. 2002. Crime, Community, and Criminal Justice. Calif. Law Rev. 90(5):1415-1422.

Sohn, J.H., J.G. Kim, and Y.J. Kim. 2015. A Study on Development of CPTED Evaluation Indicators and Assessment of Types in Neighboring Park - Focused on Neighborhood Parks in Busan -. J. Korean Soc. Civil Eng. 35(1):237-254 DOI: 10.12652/Ksce.2015.35.1.0237 